\title{
History of Computer Science as an Instrument of Enlightenment
}

\author{
Yakov Fet \\ Institute of Computational Mathematics and Mathematical Geophysics of \\ Siberian Branch of Russian Academy of Sciences, Novosibirsk, Russia \\ fetessd.sscc.ru
}

\begin{abstract}
This report focuses on the dangerous problems that are currently facing the society - the negative phenomena in development of education and science. The most important way to solve this problem seems to be education and enlightenment. It is assumed that in the history of Computer Science, the intellectual and moral heritage of this history contains a wealth of material that can be used for the dissemination of knowledge, education, and human qualities. It is proposed to significantly expand the publication and dissemination of relevant non-fiction and biographical literature.
\end{abstract}

Keywords: history of computing, cultural heritage, global problems, Rome Club, Aurelio Peccei, human qualities, education, enlightenment, Norbert Wiener, John von Neumann, Leonid Kantorovich, Aleksey Lyapunov, Donald Knuth, Andrey Ershov, Aleksander Aleksandrov.

\section{Introduction}

The study of the history of science, familiarity with the life and activities of outstanding individuals - scientists, engineers, inventors, has always been an important part of the cultural and scientific heritage.

In the middle of the $20^{\text {th }}$ century, a new stage began in the development of science, and, as we can say, in the history of human society! That was - the invention of electronic computers, the unprecedented pace of their improvement and dissemination, the creation of global information networks, as well as new means for storage and processing of huge amounts of data.

New information technologies have a strong influence on the society. They can bring people prosperity and physical and spiritual well-being. They pave the way to unprecedented opportunities for development of all areas of human activity.

\section{Danger}

Unfortunately, the achievements of information technologies, like some other results of scientific and technical progress, have their reverse side. 
The creator of cybernetics Norbert Wiener was well aware than the new means of communications and the mass media can turn to the people their dangerous consequences. Even at the dawn of computers, in 1948, in the first edition of his famous book "Cybernetics" Wiener wrote:

One of the lessons of the present book is that any organism is held together in this action by the possession of means for the acquisition, use, retention, and transmission of information. In a society too large for the direct contact of its members, these means are the press, both as it concerns books, and as it concerns newspapers, the radio, the telephone system, the telegraph, the posts, the theatre, the movies, the schools, and the church...

That system which, more than all other, should contribute to social homeostasis is thrown directly into the hands of the most concerned in the game of power and money, which we have already seen to be one of the chief anti-homeostatic elements in the community.

Today these dangerous events became threatening. The uncontrolled use of the media in the interests of commercial structures deeply influence the fall of morality, tastes and mental abilities of the population.

For example, the Vice-President of the Russian Academy of Sciences academician Aleksander Aseev in his recent interview" noted "the general decline of morality in modern Russia" as well as "rapid contamination of the research and education sector of the country".

This case relates to Russia. But it can be assumed that similar signs could be observed in some other countries.

\section{$3 \quad$ Human Qualities}

The considered events can be seen as one of the global challenges facing the society today. It is not the first time when history poses to the reasonable minded scientists some complicated tasks related to the protection of society against various threats. As you know, in the middle of the $20^{\text {th }}$ century several prominent scientists and humanists created an international social group, which received the name of the "Club of Rome". One of the organizers of this Club and its first President was the famous Italian social activist, scientist and industrialist, Aurelio Peccei (1908-1984).

The main objective of the Club of Rome was to attract attention of the world community to the global problems threatening the existence and well-being of mankind. To do this, the members of the Rome Club, together with visiting scientists from different countries and professions, prepared so-called "Reports of the Rome Club". One of the first Reports considered environmental hazards associated with unnecessarily high consumption of natural resources and the pollution of environment.

1 Newspaper “Science in Siberia” / May 22, 2013. - P. 3. (In Russian). 
In 1977, Aurelio Peccei published his famous book "Human Quality"2. The main idea of Peccei was that for successful solving complex and dangerous natural, economic, and many other problems of the community, the community should first of all improve the human qualities of its members. Peccei wrote in his book:

In the end the problems come to the human qualities and the way of their improvement...

Until our so-called technologic society becomes as well a human society, violence will proceed its triumphal demonstration and we will continue to fight special cases of this general phenomenon without understanding the origins of the violence...

The main problem is - how can we get the spark which will kindle the flame of developing the human qualities...

These conclusions were written by an experienced, wise, and honest man, whose whole life was dedicated to one purpose: to help people in solving their extremely complex, vital issues. These are also valid with respect to all the issues that we are concerned about to-day. Watching the current negative events, we must unconditionally agree with the conclusions of Aurelio Peccei. The only remedy that we can offer in order to kindle the flame could be the enlightenment.

The History of Science as well as History of Computer Science are quite important tools. A special part in the dissemination of true human culture and high moral principles is played by the study of biographies of outstanding scientists, engineers, and inventors. There are good reasons for the opinion that in the scientific community the level of morality is much higher than in most other sections of society.

Dissemination of reliable information about our heroes and the instilling of their human qualities in our contemporaries, seems to be an efficient instrument for enlightenment.

\section{Some Examples}

At different times, the lives of distinguished personalities, their scientific achievements and moral honesty served as the source of education and emulation. Naturally, it concerns also the heroes of Computer Science. We can cite here some examples from well-known memoir literature:

\section{Norbert Wiener}

Norbert Wiener was deeply concerned about his younger colleagues. He displayed lavish attention to the new teachers of the Faculty of Mathematics. He invited them for breakfast and dinner, and in the first few weeks often went to their rooms.

Norman Levinson wrote: he asked me to check the manuscript of his new book. I found a gap in the proof and proved a Lemma to correct this deficiency. Wiener then sat down at the typewriter, typed my Lemma, put my name down and sent to the journal. It is not often that a distinguished Professor acts as a Secretary of his young pupil.

2 Aurelio Peccei. Human Quality / Pergamon Press, 1977. 
His colleagues and students have kept alive the memory of him as a teacher. They also remember the inspiring enthusiasm with which he treated all kinds of rigorous intellectual activity. Amar Bose said: "I could never thank Wiener enough for the education that he gave me. And most of all-he gave me faith in the incredible potential inherent in each of us"3.

\section{John von Neumann}

Von Neumann was always ready to help anyone who came to him for advice. He was sincerely interested in any difficult problem. Von Neumann taught me mathematics more than anyone else. As for the nature of creative thinking of a mathematician, I learned from him more than I could learn without him in my whole life. If he analyzed a problem, the need for its further consideration disappeared.

Only a great mind could make such significant contributions to science as was made by von Neumann. Impeccable logic was the most characteristic feature of his thinking. He seemed a perfect logical machine with carefully fitted gears. Listening to von Neumann one begins to understand how the human brain has to work. ${ }^{4}$

\section{Leonid Kantorovich}

Academician Israel Gelfand said:

The talent of Kantorovich is obvious. But the talent as such is not much of a gift: you should be able to use it. Meanwhile, the scientific gift is not all a person needs. The humane is primary, the scientific is secondary.

Why do I consider Leonid Kantorovich to be a genius? It is very simple he combines in himself two cultures: the first one pertaining to the humanities and the second one pertaining to mathematics... In the $20^{\text {th }}$ century, very few people were capable of such a synthesis... What we see is an integral inner spirituality that equally affects all areas of his work ${ }^{5}$.

\section{Igor Poletaev about Aleksey Lyapunov}

The scientific truth was his sacrificial altar, and the search for the truth was his religion. His attitude to cybernetics resembled the attitude of a priest to his religion. His self-denying and chivalrous serving the truth was supplemented with his fascinated personality and his ability to be precise and understandable at the same time. $<\ldots>$. Even disputable opinions sounded attractive and almost convincing, when he was talking. Every conversation with him was an intellectual event and an aesthetic experience ${ }^{6}$.

3 David Jerison and Daniel W. Stroock. Norbert Wiener / Proc. of Symposia in Pure Math., Vol. 60, 1997 / The Legacy of Norbert Wiener: A Centennial Symp. in Honor of the $100^{\text {th }}$ Anniv. of His Birth. - Providence, RI: AMS.

4 Eugene P. Wigner. In: Yearbook of the American Philosophical Society, 1957.

5 I.M. Gelfand. Leonid Kantorovich and the Synthesis of Two Cultures / In: Leonid Vital'evich Kantorovich: A Man and a Scientist. Vol. 1. / - Novosibirsk: SB RAS Publ. House, 2002 (- in Russian).

6 Ya. Fet. Stories about Cybernetics / Novosibirsk: SB RAS Publ. House, 2007. - P 40 (- in Russian). 


\section{Donald Knuth about Andrey Ershov}

The conference on Algorithms in Modern Mathematics and Computer Science held in Urgench, in 1979, was one of the most memorable events of my life. Although Andrey and I were officially listed as co-chairmen of that meeting, the truth is that Andrey took care of $99 \%$ of the details, while I was able to relax and enjoy the proceedings and to learn important things from the many people I met there. Such an experience is a once-in-alifetime thing, and I hope it will be possible for many other computer scientists to participate in a similar event if someone else is inspired to follow Andrey's example. During that week I got to know him much better than ever before, and I was especially struck by the brilliant way he filled numerous roles: a conference leader, organizer, philosopher, speaker, translator, and editor ${ }^{7}$.

\section{Aleksander Aleksandrov}

Professor Aleksandrov wrote ${ }^{8}$ :

Primarily in general education and, therefore, especially in the school teaching there should be, I think, historical education. It must give account of the development of nations, their material and spiritual culture, and science in particular. It should contain vivid descriptions of the dramatic events and remarkable personalities that would serve as cultural and educational lessons for young people. Thousands of Shakespeare's dramas and Tolstoy's novels were composed and performed in history. History is marvellous, inspiring, and gives us profound lessons.

\section{$5 \quad$ Our Activities}

Of course, biographical information about the heroes of the history of science, history of Computer Science, is continuously published in various books, magazines, and virtual museums. We should note the archives of Charles Babbage Institute, the databases of the Society of Information Technologies, the "IEEE Annals of the History of Computing", and a number of other sources. An important event in this series was the publication in 1999 of the report "History in the Computing Curriculum" "9 prepared by the IFIP Joint Task Group.

Considerable attention to biographical materials is paid in the Proceedings of IFIP Congresses, conferences on the history of Computer Science, which are periodically held in different parts of the world by the WG 9.7 as well as this London conference "Making the History of Computing Relevant".

7 Donald Knuth. In: "Programming" / Moscow: Nauka, 1990, No. 1.

8 Academician A.D. Aleksandrov. Reminiscences. Publications. Materials / Moscow: Nauka, 2002. - P. 307 (- in Russian).

9 J. Impagliazzo, M. Campbell-Kelly, G. Davis, J.A.N. Lee, M.R. Williams. History in the Computing Curriculum / Annals of the History of Computing, vol. 21, no 1, January-March 1999. - Pp. 4-16. 
However, in most known publications the authors focus their attention on the description of scientific and technical developments and achievements. Very seldom will you find here less formal information about the personal features of the protagonists. Apparently, there is a need for special books, maybe a special international journal, with an emphasis on personal characteristics of the scientists.

\section{Conclusion}

It is appropriate to say here about investigations on the History of Computing which are conducted in Russia. In particular, for a number of years, our Institute carries out corresponding research. We are publishing a series of scientific-biographical books about Russian and foreign Computer Pioneers. Presenting in these books the life and the work of our heroes, we pay special attention to their personal qualities. Some examples of the book titles are: "Essays on the History of Computer Science in Russia", "Leonid Vital'evich Kantorovich: a Man and a Scientist", Aleksey Andreevich Lyapunov. $100^{\text {th }}$ Anniversary of the Birth"

As of today, we have published 11 books, with the total volume above 5000 pages. Naturally, our books are printed in Russian. However, an English translation of the Summary, Foreword and Contents is included in each volume. We hope that reading of these reference materials is sufficient to get an idea of the corresponding Russian book. In addition, we are printing each year a booklet «Book Series "History of Computing"» (in English), which contains the brief details of all previously published books.

Probably, it would be useful to select definite parts of the mentioned books and publish them in English. 